\title{
Oncologic Outcomes of Salvage Chemotherapy in Patients with Recurrent or Metastatic Lesions after Radical Nephroureterectomy: A Multi-Institutional Retrospective Study
}

\author{
Masaomi lkeda ${ }^{a}$ Kazumasa Matsumoto ${ }^{a}$ Takahiro Hirayama $^{a}$ Dai Koguchi ${ }^{b}$ \\ Yasukiyo Murakami ${ }^{a}$ Daisuke Matsudac Norihiko Okuno ${ }^{d}$ Takuji Utsunomiya ${ }^{\mathrm{c}}$ \\ ${\text { Yoshinori Taokab }{ }^{b} \text { kira Irie }}^{f}$ Masatsugu Iwamura ${ }^{a}$ \\ aDepartment of Urology, Kitasato University School of Medicine, Sagamihara, Japan; bepartment of Urology, \\ Kitasato University Medical Center, Saitama, Japan; 'Department of Urology, Higashiyamato Hospital, Tokyo, Japan; \\ ${ }^{\mathrm{d} D e p a r t m e n t}$ of Urology, National Hospital Organization Sagamihara Hospital, Sagamihara, Japan; ${ }^{\text {eDepartment of }}$ \\ Urology, Kanagawa Prefectural Federation of Agricultural Cooperatives for Health and Welfare Sagamihara Kyodo \\ Hospital, Sagamihara, Japan; fDepartment of Urology, Kitasato University Kitasato Institute Hospital, Tokyo, Japan
}

\section{Keywords}

Liver metastasis · pT stage · Short time to recurrence · Salvage chemotherapy · Radical nephroureterectomy

\begin{abstract}
Background: Radical nephroureterectomy (RNU) is the standard treatment for patients with upper tract urothelial carcinoma (UTUC). However, approximately $25 \%$ of patients experience recurrence or metastasis after RNU. This study evaluated the clinical outcome and efficacy of salvage chemotherapy (SC) after recurrence or metastasis. Patients and Methods: Of the 441 nonmetastatic UTUC patients who underwent RNU, 147 patients with recurrent or metastatic lesions were analyzed; patients with bladder cancer recurrence were excluded. Time from disease recurrence or metastasis to cancer-specific survival (CSS) was estimated by the Kaplan-Meier method. Multivariate analyses were performed with the Cox proportional hazards regression mod-
\end{abstract}

el, controlling for the effects of clinicopathological factors. Results: The median time from RNU to disease recurrence or metastasis was 13.2 months. In the recurrent or metastatic sites, 31 cases (21\%) were liver. In multivariate analyses, pT stage ( $\geq \mathrm{pT} 3)$, time to recurrence ( $<12$ months), and liver metastasis were independently predictive factors. In the risk stratification model for CSS after recurrence, patients were categorized into 2 groups based on PT stage, time to recurrence, and liver metastasis. The low-risk group (0-1 risk factors) included 87 patients, and the high-risk group (2-3 risk factors) included 60 patients. In the high-risk group, 27 patients received SC. The probability of CSS after recurrence or metastasis was higher in patients in the SC group compared to the non-SC group (9.5 vs. 3.7 months; $p<0.001)$. Conclusion: Two or more risk factors defined the high-risk group for patients with recurrence or metastasis after RNU. SC was associated with improved survival in patients with high-risk UTUC.

(c) 2020 The Author(s)

Published by S. Karger AG, Basel karger@karger.com www.karger.com/che

Karger ${ }^{\prime \prime} \div$

BOPEN ACCESS
(C) 2020 The Author(s)

Published by S. Karger AG, Basel

This is an Open Access article licensed under the Creative Commons Attribution-NonCommercial-4.0 International License (CC BY-NC) (http://www.karger.com/Services/OpenAccessLicense), applicable to the online version of the article only. Usage and distribution for commercial purposes requires written permission.
Kazumasa Matsumoto

Department of Urology, Kitasato University School of Medicine

1-15-1 Kitasato, Minami-ku

Sagamihara 252-0374 (Japan)

kazumasa@cd5.so-net.ne.jp 


\section{Introduction}

Upper tract urothelial carcinoma (UTUC) is a rare disease, accounting for only $5-10 \%$ of all urothelial malignancies $[1,2]$. Radical nephroureterectomy (RNU) with excision of the bladder cuff is considered to be the standard surgical treatment for patients with nonmetastatic UTUC and offers adequate local tumor control and longterm survival. However, approximately $25 \%$ patients experience recurrence or metastasis after RNU, and cancerspecific mortality after recurrence or metastasis remains poor $[3,4]$.

Urologists may administer perioperative chemotherapy, such as neoadjuvant or adjuvant chemotherapy (AC), to improve prognosis even slightly. Although there were no randomized trials and no prospective studies, available studies suggest that neoadjuvant and $\mathrm{AC}$ are associated with improved survival in patients with UTUC [57]. Recently, AC after RNU was reported to have significantly improved disease-free survival in patients with locally advanced UTUC in the POUT trial, a phase 3 randomized controlled trial [8]. Salvage chemotherapy (SC) is considered when there is recurrence or metastasis after RNU.

The natural progression of UTUC from RNU to disease recurrence or metastasis has been intensively investigated [9-12]. However, few studies have focused on the clinical outcomes of patients who experienced disease recurrence or metastasis after RNU, and the details are still poorly understood. This study evaluated whether clinicopathological factors at time of disease recurrence or metastasis were associated with cancer-specific outcomes in these patients and whether SC was effective. In addition, for a multi-institutional cohort of patients who experienced disease recurrence or metastasis after RNU for UTUC, we determined which patients qualified for SC.

\section{Patients and Methods}

\section{Patient Selection}

We retrospectively reviewed clinical data for 441 nonmetastatic UTUC patients who underwent RNU between 1990 and 2015, excluding 8 patients who received neoadjuvant chemotherapy. Of the 441 patients who underwent RNU, 147 patients (33\%) experienced recurrence or metastasis; patients with bladder cancer recurrence were excluded. Among them, 74 (50\%) patients received SC, and the remaining 73 (50\%) received best supportive care (BSC). Although this study has a nonrandomized retrospective design, all recurrent or metastatic patients who were usually recommended for additional therapy after RNU received informed consent for SC. Ultimately, the administration of SC was determined by consultation with the urologist in charge and in accordance with the patients on the basis of their performance status, desire for treatment, and renal function.

\section{Clinicopathological Evaluation}

The following data on patient characteristics were collected: age at recurrence or metastasis, sex, surgery approach, change rate of postoperative estimated glomerular filtration rate (eGFR), history of AC, mortality, and pathological status (including histology, primary organ, $\mathrm{pT}$ stage, $\mathrm{pN}$ stage, tumor grade, concomitant carcinoma in situ, tumor architecture, lymphovascular invasion, and soft tissue surgical margin). Patients were stratified into 3 groups based on the change in rate between pre- and postoperative eGFR: normal change (increased or $<10 \%$ decrease), moderate change (10-30\% decrease), and severe change ( $>30 \%$ decrease) [13]. Tumor grade was assessed according to the 1998 World Health Organization/International Society of Urologic Pathology consensus [14]. The 2002 TNM Classification of the International Union for Cancer Control and American Joint Committee on Cancer Guidelines was used to determine cancer stage [15]. Surgical specimens were processed according to standard pathological procedures at each institution. Tumor location was divided into 2 areas (renal pelvis and ureter) based on the site of the dominant lesion [16].

\section{Follow-Up of Patients}

Patients were generally followed every 3 months for the first 2 years after RNU, then every 6 months for the next 3 years, and annually thereafter. Follow-up consisted of physical examinations, routine blood tests, urinary cytology, and cystoscopic evaluation. Computed tomography evaluations of local recurrence and metastatic lesions, as well as chest X-rays, were performed every 6 months for the first 2 years and annually thereafter. Bone scans were performed when disease progression was clinically indicated. On the basis of patients' medical records, the time from recurrence or metastasis to cancer-specific survival (CSS) was calculated. Disease recurrence was defined as failure in nonbladder lesions, such as local recurrence at the surgery site, in regional lymph nodes, and (or) distant metastasis. Sites of distant metastases were defined as the liver, lung, bone, distant lymph nodes, brain, and others (including the peritoneum, skin, contralateral upper tract, and other organs).

\section{Statistical Analysis}

The clinicopathological variables in each group were compared using the Kruskal-Wallis test, the $\chi^{2}$ test, and the Fisher's exact test. CSS probabilities after recurrence or metastasis were estimated by the Kaplan-Meier method and compared among groups with the log-rank test. Multivariate analyses were performed with the Cox proportional hazards regression model, controlling for age at recurrence or metastasis ( $<70$ vs. $\geq 70$ years), sex (male vs. female), eGFR change (normal change vs. moderate change vs. severe change), pT stage (pT2 or lower vs. pT3 or higher), time from RNU to recurrence or metastasis (time to recurrence [TTR]) ( $<12$ vs. $\geq 12$ months), lung metastasis (yes vs. no), liver metastasis (yes vs. no), bone metastasis (yes vs. no), lymph node metastasis (yes vs. no), AC status (yes vs. no), and SC status (yes vs. no) with CSS after recurrence or metastasis. Statistical analyses were performed with Stata version 13 for Windows (Stata, Chicago, IL, USA). All $p$ values were 2 -sided, and $p<0.05$ was considered statistically significant.
Salvage Chemotherapy for Recurrence after Radical Nephroureterectomy
Chemotherapy 2020;65:134-140 DOI: $10.1159 / 000511667$ 
Table 1. Clinicopathological characteristics of 147 recurrence or metastasis patients after RNU according to SC status

\begin{tabular}{|c|c|c|c|}
\hline Characteristics & $\begin{array}{l}\text { Patients } \\
\text { administered SC, } \\
n=74\end{array}$ & $\begin{array}{l}\text { Patients not } \\
\text { administered SC, } \\
n=73\end{array}$ & $\begin{array}{l}p \\
\text { value }\end{array}$ \\
\hline \multicolumn{4}{|l|}{ Age at recurrence, years } \\
\hline Median, IQR & $68(62-74)$ & $73(65-78)$ & 0.009 \\
\hline \multicolumn{4}{|l|}{ Sex, $n(\%)$} \\
\hline Male & $57(77.0)$ & $47(64.4)$ & \multirow[t]{2}{*}{0.092} \\
\hline Female & $17(23.0)$ & $26(35.6)$ & \\
\hline \multicolumn{4}{|l|}{ Surgery approach, $n(\%)$} \\
\hline Open & $45(60.8)$ & $49(67.1)$ & \multirow[t]{2}{*}{0.425} \\
\hline Laparoscopic & $29(39.2)$ & $24(32.9)$ & \\
\hline \multicolumn{4}{|l|}{ Primary organ, $n(\%)$} \\
\hline Renal pelvis & $31(41.9)$ & $39(53.4)$ & \multirow[t]{2}{*}{0.162} \\
\hline Ureter & $43(58.1)$ & $34(46.6)$ & \\
\hline \multicolumn{4}{|c|}{ Change rate of eGFR, $n(\%)$} \\
\hline $\begin{array}{l}\text { Normal (increase } \\
\text { or }<10 \% \text { ) }\end{array}$ & $31(41.9)$ & $31(42.5)$ & \multirow[t]{3}{*}{0.931} \\
\hline Moderate (10-30\%) & $27(36.5)$ & $25(34.2)$ & \\
\hline Severe $(>30 \%)$ & $16(21.6)$ & $17(23.3)$ & \\
\hline \multicolumn{4}{|l|}{ Histopathology type, $n(\%)$} \\
\hline UC & $64(86.5)$ & $63(86.3)$ & \multirow[t]{2}{*}{0.974} \\
\hline Nonpure UC & $10(13.5)$ & $10(13.7)$ & \\
\hline \multicolumn{4}{|l|}{ Pathological T stage, $n(\%)$} \\
\hline$\leq \mathrm{pT} 2$ & $27(36.5)$ & $24(32.9)$ & \multirow[t]{2}{*}{0.646} \\
\hline$\geq \mathrm{pT} 3$ & $47(63.5)$ & $49(67.1)$ & \\
\hline \multicolumn{4}{|l|}{ Lymph node status, $n(\%)$} \\
\hline $\mathrm{pN} 0 / \mathrm{N} x$ & $61(82.4)$ & $66(90.4)$ & \multirow[t]{2}{*}{0.158} \\
\hline $\mathrm{pN}+$ & $13(17.6)$ & $7(9.6)$ & \\
\hline \multicolumn{4}{|l|}{ Tumor grade, $n(\%)^{\mathrm{a}}$} \\
\hline G1/G2 & $39(53.4)$ & $34(47.2)$ & \multirow[t]{2}{*}{0.455} \\
\hline G3 & $34(46.6)$ & $38(52.8)$ & \\
\hline \multicolumn{4}{|l|}{ Concomitant CIS, $n(\%)^{\mathrm{b}}$} \\
\hline Absent & $61(82.4)$ & $58(81.7)$ & \multirow[t]{2}{*}{0.907} \\
\hline Present & $13(17.6)$ & $13(18.3)$ & \\
\hline \multicolumn{4}{|c|}{ Tumor architecture, $n(\%)^{\mathrm{c}}$} \\
\hline Papillary & $38(55.9)$ & $41(61.2)$ & \multirow[t]{2}{*}{0.531} \\
\hline Sessile & $30(44.1)$ & $26(38.8)$ & \\
\hline \multicolumn{4}{|c|}{ Lymphovascular invasion, $n(\%)^{\mathrm{d}}$} \\
\hline Absent & $26(40.0)$ & $20(29.0)$ & \multirow[t]{2}{*}{0.180} \\
\hline Present & $39(60.0)$ & $49(71.0)$ & \\
\hline \multicolumn{4}{|c|}{ Soft tissue surgical margin, $n(\%)$} \\
\hline Negative & $63(85.1)$ & $55(75.3)$ & \multirow[t]{2}{*}{0.136} \\
\hline Positive & $11(14.9)$ & $18(24.7)$ & \\
\hline AC, $n(\%)$ & & & \\
\hline No & $48(64.9)$ & $47(64.4)$ & 0.951 \\
\hline Yes & $26(35.1)$ & $26(35.6)$ & \\
\hline Follow-up, months & & & \\
\hline Median, IQR & $28.3(18.7-50.2)$ & $21.6(8.7-45.2)$ & 0.027 \\
\hline
\end{tabular}

IQR, interquartile range; eGFR, estimated glomerular filtration rate; UC, urothelial carcinoma; CIS, carcinoma in situ; AC, adjuvant chemotherapy; RNU, radical nephroureterectomy; SC, salvage chemotherapy. ${ }^{a}$ Two patients with unknown tumor grade. ${ }^{\mathrm{b}}$ Two patients with unknown CIS. ${ }^{c}$ Twelve patients with unknown tumor architecture. ${ }^{\mathrm{d}}$ Thirteen patients had no lymphovascular invasion status.
Table 2. Sites of recurrence or metastasis in 147 patients

\begin{tabular}{lc}
\hline Region & Patients, $n(\%)$ \\
\hline Lymph node & $57(39)$ \\
Lung & $43(29)$ \\
Bone & $41(28)$ \\
Liver & $31(21)$ \\
Local & $21(14)$ \\
Peritoneal dissemination & $9(6)$ \\
Lateral upper tract & $8(5)$ \\
Brain & $4(3)$ \\
Other & $12(8)$ \\
\hline
\end{tabular}

\section{Results}

Demographic and clinicopathological characteristics of 147 recurrence or metastasis patients are summarized in Table 1. The median age at recurrence or metastasis of all cohorts was 69 years (interquartile range [IQR], 63-77 years), and the median TTR was 13.2 months (IQR, 5.728.7 months). For 68 patients (46\%), the TTR was $<12$ months. During follow-up, 100 (68\%) of 147 patients died due to UTUC, and the median survival time from recurrence or metastasis to cancer death was 9.9 months. In the recurrent or metastatic sites, 57 (39\%) cases were lymph node, 43 (29\%) were lung, 41 (28\%) were bone, and 31 (21\%) were liver (Table 2).

Of the 147 patients with recurrence or metastasis disease after RNU, 74 (50\%) received SC, and the remaining 73 (50\%) received BSC. Among the patients who received SC, 36 received the methotrexate, vinblastine, doxorubicin, and cisplatin (MVAC) regimens, 34 received the gemcitabine and cisplatin (GC) regimens, 11 received the gemcitabine and paclitaxel regimens, 1 received the pembrolizumab regimen, and 7 received other regimens. The number of SC regimens was 1 regimen in 60 cases $(81 \%)$, 2 regimens in 13 cases (18\%), and 3 regimens in only one case (1\%). Patients received a median 3 courses (IQR, 2-4 courses) of SC. The majority of patients received platinum-based SC, but cisplatin was reduced by $20-50 \%$ in cases of impaired renal function. The median survival time was 12.4 months in the SC group and 6.9 months in the BSC group, respectively. The group who received SC had approximately twice the longer survival time, but there was no statistically significant difference $(p=0.179)$. In the SC group, the median survival times of patients who received $\mathrm{AC}$ and patients who did not receive $\mathrm{AC}$ were 13.9 and 11.3 months, respectively $(p=0.237)$.

Table 3 shows a summary of the univariate and multivariate analyses for CSS. In multivariate analyses, $\mathrm{pT}$ 
Table 3. Univariate and multivariate Cox proportional hazards analysis for the prediction of CSS in 147 patients with recurrence or metastasis after RNU

\begin{tabular}{|c|c|c|c|}
\hline \multirow[t]{2}{*}{ Factor } & \multirow{2}{*}{$\frac{\text { Univariate }}{p \text { value }}$} & \multicolumn{2}{|l|}{ Multivariate } \\
\hline & & HR (95\% CI) & $p$ value \\
\hline Age $<70$ years (reference: $\geq 70$ years) & 0.050 & $1.50(0.999-2.260)$ & 0.050 \\
\hline Female (reference: male) & 0.717 & - & - \\
\hline eGFR severe change (reference: normal) & 0.118 & - & - \\
\hline eGFR moderate change (reference: normal) & 0.973 & - & - \\
\hline$\geq \mathrm{pT} 3$ (reference: $\leq \mathrm{pT} 2$ ) & 0.003 & $1.72(1.083-2.722)$ & 0.021 \\
\hline$<12$ months (reference: $\geq 12$ months) & 0.018 & $1.54(1.033-2.290)$ & 0.034 \\
\hline Lung metastasis (reference: no) & 0.081 & - & - \\
\hline Liver metastasis (reference: no) & $<0.001$ & $2.27(1.419-3.628)$ & 0.001 \\
\hline Lymph node metastasis (reference: no) & 0.688 & - & - \\
\hline Bone metastasis (reference: no) & 0.187 & - & - \\
\hline AC (reference: no) & 0.350 & - & - \\
\hline SC (reference: no) & 0.181 & - & - \\
\hline
\end{tabular}

$\mathrm{CI}$, confidence interval; HR, hazard ratio; eGFR, estimated glomerular filtration rate; RNU, radical nephroureterectomy; SC, salvage chemotherapy; CSS, cancer-specific survival; AC, adjuvant chemotherapy.

Fig. 1. Kaplan-Meier curves for CSS in the 147 recurrence or metastasis patients after RNU for UTUC, stratified by risk group. RNU, radical nephroureterectomy; UTUC, upper tract urothelial carcinoma; CSS, cancer-specific survival.

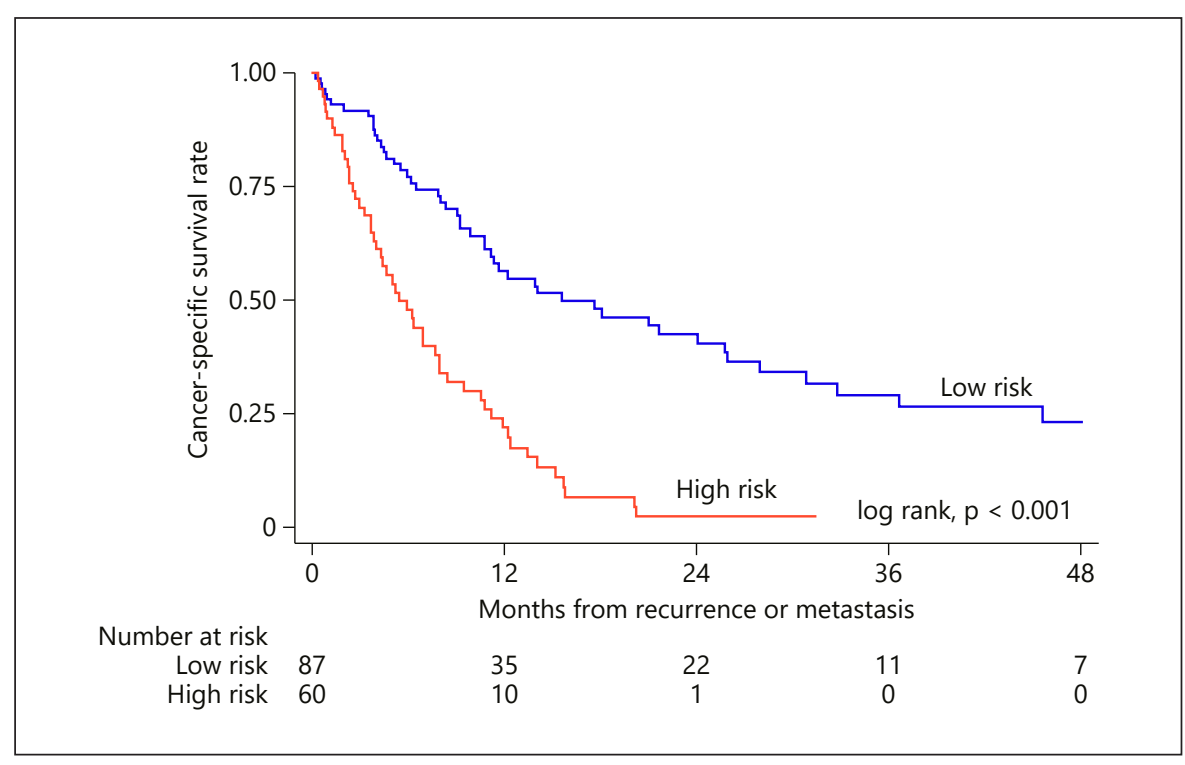

stage ( $\geq$ pT3), TTR $<12$ months, and presence of liver metastasis were independently predictive factors. For the risk stratification model, patients were categorized into 2 groups based on pT stage, TTR, and liver metastasis (Fig. 1). The low-risk group (0-1 risk factors) included 87 patients, and the high-risk group (2-3 risk factors) included 60 patients. The median survival time in the lowrisk groups and high-risk groups was 15.6 and 5.4 months, respectively $(p<0.001)$. Fifty-two patients had disease re- currence or metastasis after AC, and 26 (50\%) were highrisk cases. These patients were more frequent than highrisk cases who relapsed without AC (34 of 95, 36\%) but were not significantly different. Figure 2 shows the Kaplan-Meier curves for CSS according to the SC treatment strategy in each group. In the low-risk group, 47 patients (54\%) received SC; in the high-risk group, 27 patients (45\%) were treated with SC. In the low-risk group, no statistically significant differences were seen between the SC 
Fig. 2. Kaplan-Meier curves for CSS in lowrisk group (a) and high-risk group (b) patients, stratified by SC status. SC, salvage chemotherapy; CSS, cancer-specific survival.

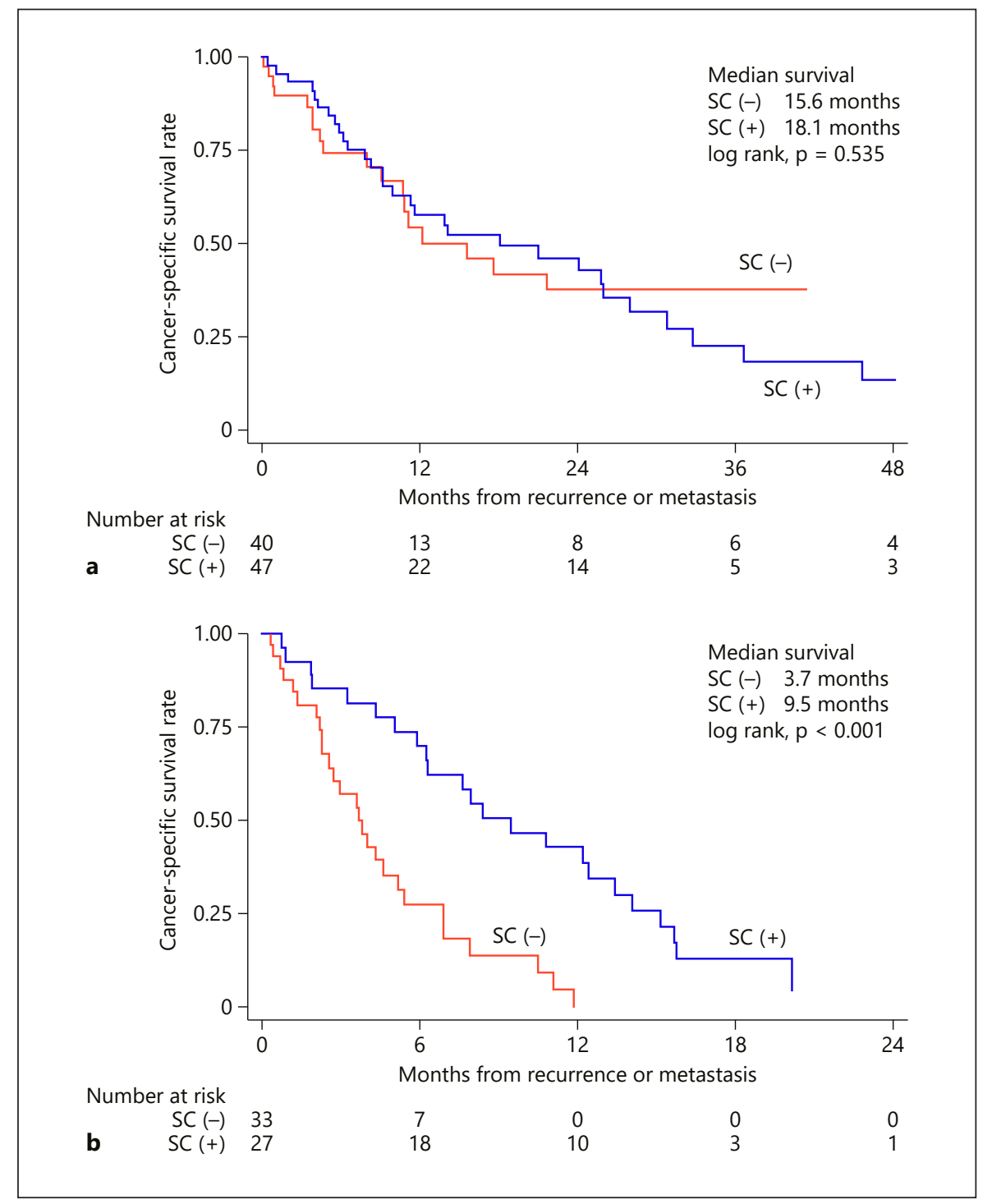

treatment strategies regarding median survival time ( 15.6 vs. 18.1 month; $p=0.535$; Fig. $2 \mathrm{a}$ ). However, the median survival time was longer in patients in the SC group compared to the non-SC group in high-risk group (9.5 vs. 3.7 months; $p<0.001$; Fig. 2b).

\section{Discussion}

The survival of patients with UTUC who experienced disease recurrence or metastasis after RNU was poor. Most of these patients died due to UTUC within 1 year after recurrence or metastasis, and only few patients (19\%) survived beyond 2 years [3]. Indeed, the median survival time from recurrence or metastasis to cancer death was 9.9 months in our study. The 2- and 3-year CSS rates after recurrence or metastasis were 24 and $16 \%$, respectively.

A few studies have focused on the predictive factors of patients who experienced recurrence or metastasis after RNU. In the present study, we found that $\mathrm{pT}$ stage ( $\geq$ pT3), TTR $<12$ months, and the presence of liver metastasis were significant predictors of post-recurrence cancer-specific mortality according to a multivariate analysis. Generically, nonorgan-confined pathological stage ( $\geq$ pT3) is an established predictive factor for outcomes prognostication after RNU [4, 11, 17, 18]. Even after recurrence or metastasis, patients with nonorgan- 
confined UTUC have a worse survival rate than those with organ-confined UTUC. The low survival rate is possibly attributable to a higher burden of disease that cannot be easily identified, such as micrometastatic cancer $[3,19]$.

A TTR of $<12$ months and the presence of liver metastasis are also very important factors. Rink et al. [3] reported the risk of cancer-specific mortality following recurrence after RNU. Of 2,494 UTUC patients treated with RNU without neoadjuvant chemotherapy, 597 patients who experienced disease recurrence were analyzed. They found that a shorter time ( $<12$ months) from RNU to disease recurrence is associated with poorer survival after disease recurrence, results which were similar to those in our study. In a study of urothelial carcinoma of the bladder, Mitra et al. [20] also reported similar results.

The liver is the main site of metastatic disease, and liver metastases remain a major barrier in the treatment of many malignancies [21]. For the importance of liver metastasis, prognostic risk factors (sometimes called Bajorin risk factors) model and a report by Bellmunt et al. [22] may be helpful $[22,23]$. Bajorin et al. [23] reported that a Karnofsky performance status less than $80 \%$ and the presence of visceral metastasis (lung, liver, and [or] bone) were independent prognostic factors of poor survival after MVAC chemotherapy. Bellmunt et al. [22] reported that the same Bajorin risk factors have a poor survival even after treatment with paclitaxel, cisplatin, and gemcitabine regimen. It should be noted that these studies included a very heterogeneous patient cohort with unresectable and (or) metastatic urothelial cancer of any type (bladder, ureter, and pelvis) compared to our study of recurrence or metastasis after treatment with RNU for UTUC. Although there are differences in patient backgrounds, the presence of liver metastasis is one of the key prognostic factors. However, it is unknown whether the mechanism that affects the prognosis of liver metastasis is direct or indirect. In fact, once a liver recurrence has developed, patients will have a poor prognosis regardless of primary tumor characteristics [24]. Although the resection of isolated liver metastasis provides a good longterm CSS benefit when treating selected patients with colorectal cancer, its role in patients with liver metastasis is not well defined in patients with other types of cancer $[24,25]$. Albumin, which is produced in the liver, reflects nutritional status and inflammatory processes and has been demonstrated to be prognostic factor in a number of malignancies [26,27]. Thus, hypoalbuminemia may be associated with prognosis as an indirect mechanism of liver metastasis.

Salvage Chemotherapy for Recurrence after Radical Nephroureterectomy
Finally, we found that SC was associated with improved survival in the multivariate analyses, especially in the high-risk group. However, the benefit of SC was biased by the fact that it was the younger and healthier patients who received SC, and it may be that the apparent survival time was prolonged. In general, elderly patients tended to lose the opportunity for the therapeutic intervention (such as SC) compared with younger patients. Although an accurate prediction of clinical outcomes after disease recurrence or metastasis can help therapeutic intervention, it is more important to select the patients who may benefit from SC on the basis of the ability to preserve their quality of life.

The present study has several limitations. One major limitation is that this is a retrospective study without randomization, which may have introduced bias in the patient selection process. Second, all cohort and high-risk groups were relatively small. Third, pembrolizumab was used in only one case during the observation period in this study, which may be insufficient for evaluation in the immunotherapy era. However, pembrolizumab is positioned as a second-line treatment, and although the effectiveness of AC is being shown recently [8], the majority of recurrence or metastasis after RNU still require first-line chemotherapy. Selecting the patients who should receive SC is an important role. Finally, because our cohort included patients from several different institutions, RNU was performed by multiple surgeons, and the present study lacks a central pathological review. Nevertheless, clinicopathological factors were almost nonbiased, and we found that pT stage $(\geq \mathrm{pT} 3)$, TTR $<12$ months, and the presence of liver metastasis were important predictors of post-recurrence CSS. Using these factors for risk classification may help to properly screen the patients who should receive SC.

\section{Conclusion}

In this multi-institutional retrospective study, we found that 2 or more risk factors $(\geq \mathrm{pT} 3, \mathrm{TTR}<12$ months, and presence of liver metastasis) defined the high-risk group for patients with recurrence or metastasis after RNU. SC was associated with improved survival in patients with high-risk UTUC. 


\section{Statement of Ethics}

This study was approved by the institutional review board at 6 Kitasato university-affiliated hospitals (B15-25) and was conducted in accordance with the Declaration of Helsinki and its later amendments.

\section{Conflict of Interest Statement}

The authors have no conflicts of interest to declare.

\section{Funding Sources}

There are no funding sources to declare.

\section{Author Contributions}

M.I. (First author): project development, data collection, data analysis, manuscript writing, and submission. K.M.: project development, data analysis, and manuscript writing and editing. T.H., D.K., Y.M., Y.T., and A.I.: data collection and project development. D.M., N.O., and T.U.: data collection. M.I.: project development and manuscript editing.

\section{References}

1 Siegel RL, Miller KD, Jemal A. Cancer statistics, 2018. CA Cancer J Clin. 2018 Jan;68(1): 7-30.

2 Roupret M, Babjuk M, Comperat E, Zigeuner R, Sylvester RJ, Burger M, et al. European association of urology guidelines on upper urinary tract urothelial carcinoma: 2017 update. Eur Urol. 2018 Jan;73(1):111-22.

3 Rink M, Sjoberg D, Comploj E, Margulis V, Xylinas E, Lee RK, et al. Risk of cancer-specific mortality following recurrence after radical nephroureterectomy. Ann Surg Oncol. 2012 Dec;19(13):4337-44

4 Margulis V, Shariat SF, Matin SF, Kamat AM, Zigeuner R, Kikuchi E, et al. Outcomes of radical nephroureterectomy: a series from the upper tract urothelial carcinoma collaboration. Cancer. 2009 Mar;115(6):1224-33.

5 Ikeda M, Matsumoto K, Hirayama T, Koguchi D, Murakami Y, Matsuda D, et al. Selected high-risk patients with upper tract urothelial carcinoma treated with radical nephroureterectomy for adjuvant chemotherapy: a multiinstitutional retrospective study. Clin Genitourin Cancer. 2018 Jun;16(3):e669-e75.

6 Porten S, Siefker-Radtke AO, Xiao L, Margulis V, Kamat AM, Wood CG, et al. Neoadjuvant chemotherapy improves survival of patients with upper tract urothelial carcinoma. Cancer. 2014 Jun;120(12):1794-9.

7 Seisen T, Krasnow RE, Bellmunt J, Rouprêt M, Leow JJ, Lipsitz SR, et al. Effectiveness of adjuvant chemotherapy after radical nephroureterectomy for locally advanced and/or positive regional lymph node upper tract urothelial carcinoma. J Clin Oncol. 2017 Mar;35(8):85260 .

8 Birtle A, Johnson M, Chester J, Jones R, Dolling D, Bryan RT, et al. Adjuvant chemotherapy in upper tract urothelial carcinoma (the POUT trial): a phase 3 , open-label, randomised controlled trial. Lancet. 2020 Apr;395(10232): 1268-77.

9 Martinez-Salamanca JI, Shariat SF, Rodriguez JC, Chromecki TF, Ficarra V, Fritsche HM, et al. Prognostic role of ECOG performance status in patients with urothelial carcinoma of the upper urinary tract: an international study. BJU Int. 2012 Apr;109(8):1155-61.
10 Lughezzani G, Burger M, Margulis V, Matin SF, Novara G, Roupret M, et al. Prognostic factors in upper urinary tract urothelial carcinomas: a comprehensive review of the current literature. Eur Urol. 2012 Jul;62(1):100-14

11 Chromecki TF, Bensalah K, Remzi M, Verhoest G, Cha EK, Scherr DS, et al. Prognostic factors for upper urinary tract urothelial carcinoma. Nat Rev Urol. 2011 Jul;8(8):440-7.

12 Zigeuner R, Shariat SF, Margulis V, Karakiewicz PI, Roscigno M, Weizer A, et al. Tumour necrosis is an indicator of aggressive biology in patients with urothelial carcinoma of the upper urinary tract. Eur Urol. 2010 Apr;57(4):575-81.

13 Koguchi D, Matsumoto K, Ikeda M, Yoshinori T, Hirayama T, Murakami Y, et al. Investigation of estimated glomerular filtration rate and its perioperative change in patients with upper urinary tract urothelial carcinoma: amulti-institutional retrospective study. Asia Pac J Clin Oncol. 2018 Oct;14(5):e420-e7.

14 Epstein JI, Amin MB, Reuter VR, Mostofi FK The world health organization/international society of urological pathology consensus classification of urothelial (transitional cell) neoplasms of the urinary bladder. Bladder consensus conference committee. Am J Surg Pathol. 1998 Dec;22(12):1435-48.

15 Greene FL, Page DL, Fleming ID, Fritz AG Balch CM, Haller DG, et al. AJCC cancer staging manual. 6th ed. New York: Springer; 2002.

16 Raman JD, Ng CK, Scherr DS, Margulis V, Lo$\tan \mathrm{Y}$, Bensalah K, et al. Impact of tumor location on prognosis for patients with upper tract urothelial carcinoma managed by radical nephroureterectomy. Eur Urol. 2010 Jun; 57(6):1072-9.

17 Novara G, De Marco V, Gottardo F, Dalpiaz O, Bouygues $\mathrm{V}$, Galfano A, et al. Independent predictors of cancer-specific survival in transitional cell carcinoma of the upper urinary tract: multi-institutional dataset from 3 European centers. Cancer. 2007 Oct;110(8):1715-22.

18 Langner C, Hutterer G, Chromecki T, Winkelmayer I, Rehak P, Zigeuner R.pT classification, grade, and vascular invasion as prognostic indicators in urothelial carcinoma of the upper urinary tract. Mod Pathol. 2006 Feb;19(2): $272-9$.
19 Kluth LA, Xylinas E, Kent M, Hagiwara M, Kikuchi E, Ikeda M, et al. Predictors of survival in patients with disease recurrence after radical nephroureterectomy. BJU Int. 2014 Jun; 113(6):911-7.

20 Mitra AP, Quinn DI, Dorff TB, Skinner EC, Schuckman AK, Miranda G, et al. Factors influencing post-recurrence survival in bladder cancer following radical cystectomy. BJU Int. 2012 Mar;109(6):846-54.

21 Hess KR, Varadhachary GR, Taylor SH, Wei W, Raber MN, Lenzi R, et al. Metastatic patterns in adenocarcinoma. Cancer. 2006 Apr; 106(7):1624-33.

22 Bellmunt J, Albanell J, Paz-Ares L, Climent MA, González-Larriba JL, Carles J, et al. Pretreatment prognostic factors for survival in patients with advanced urothelial tumors treated in a phase I/II trial with paclitaxel, cisplatin, and gemcitabine. Cancer. 2002 Aug;95(4):751-7.

23 Bajorin DF, Dodd PM, Mazumdar M, Fazzari M, McCaffrey JA, Scher HI, et al. Long-term survival in metastatic transitional-cell carcino$\mathrm{ma}$ and prognostic factors predicting outcome of therapy. J Clin Oncol. 1999 Oct;17(10): 3173-81.

24 Toptas T, Karalok A, Ureyen I, Tasci T, Erol O, Bozkurt $\mathrm{S}$, et al. Liver recurrence in endometrial cancer: a multi-institutional analysis of factors predictive of postrecurrence survival. Clin Exp Metastasis. 2016 Oct;33(7):707-15.

25 Rees M, Tekkis PP, Welsh FK, O’Rourke T, John TG. Evaluation of long-term survival after hepatic resection for metastatic colorectal cancer: a multifactorial model of 929 patients. Ann Surg. 2008 Jan;247(1):125-35.

26 Sonpavde G, Pond GR, Rosenberg JE, Bajorin DF, Choueiri TK, Necchi A, et al. Improved 5 -factor prognostic classification of patients receiving salvage systemic therapy for advanced urothelial carcinoma. J Urol. $2016 \mathrm{Feb}$; 195(2):277-82.

27 Forrest LM, McMillan DC, McArdle CS, Angerson WJ, Dunlop DJ. Comparison of an inflammation-based prognostic score (GPS) with performance status (ECOG) in patients receiving platinum-based chemotherapy for inoperable non-small-cell lung cancer. $\mathrm{Br} \mathrm{J}$ Cancer. 2004 May;90(9):1704-6. 